\title{
Cognitive Bias as a Mediator in the Relation Between Fear-Enhancing Parental Behaviors and Anxiety Symptoms in Children: A Cross-Sectional Study
}

\author{
Lorraine Fliek $^{1} \cdot$ Pauline Dibbets $^{1} \cdot$ Jeffrey Roelofs $^{1} \cdot$ Peter Muris $^{1,2}$
}

Published online: 10 June 2016

(c) The Author(s) 2016. This article is published with open access at Springerlink.com

\begin{abstract}
The present cross-sectional study explored the relations between fear-enhancing parenting behaviors (modeling and threat information transmission) and children's cognitive biases and anxiety symptoms. Participants were 258 children aged $7-12$ years (132 boys and 126 girls), and their mothers $(n=199)$ and/or fathers $(n=117)$. Children and parents completed the Parental Enhancement of Anxious Cognitions questionnaire, which measures parental modeling and threat information transmission, while children also filled in a scale for assessing anxiety symptoms. In addition, children conducted a number of computerized tasks for measuring confirmation and interpretation bias. The data indicated that both biases mediated the relationship between threat information transmission (of both parents) and children's anxiety symptoms. Only interpretation bias significantly mediated the relationship between modeling (of mothers) and anxiety symptoms. These findings give partial support for the hypothesis that cognitive biases play a mediating role in the relation between fear-enhancing parental behaviors and children's anxiety symptoms.
\end{abstract}

Keywords Children's anxiety symptoms · Cognitive biases $\cdot$ Parenting $\cdot$ Modeling $\cdot$ Threat information transmission

Lorraine Fliek

lorraine.fliek@maastrichtuniversity.nl

1 Clinical Psychological Science, Faculty of Psychology and Neuroscience, Maastricht University, P.O. Box 616, 6200 MD Maastricht, The Netherlands

2 Stellenbosch University, Stellenbosch, South Africa

\section{Introduction}

Fear and anxiety are normal, mild, and transient phenomena in childhood, but in a minority of children these symptoms become so intense and invalidating that they qualify as an anxiety disorder [1]. Heritability is thought to be involved in the etiology of childhood fear and anxiety problems, with behavioral-genetic studies showing that about $30 \%$ of the variation in anxiety disorders can be ascribed to genetic influences [2]. This means that environmental factors also play an important role in the development of fear and anxiety problems, and among these factors parenting behaviors are considered as particularly relevant [3].

In the current study, both parents were included, while previous studies have mostly included only mothers. The role of fathers has often been neglected, although there is some evidence suggesting that fathers play a unique and often different role than mothers in the development of anxiety problems in children (e.g., $[4,5])$. In the article we further focus on two types of parenting behaviors that, according to Rachman [6,7], are involved in the acquisition of fear and anxiety symptoms within the context of the family. The first type is known as modeling or vicarious learning and refers to the phenomenon of children learning anxious behavior after watching parents acting in a fearful way when facing certain stimuli and situations. The second type is threat information transmission, which is concerned with parents installing fear and anxiety in their offspring by telling their children about the dangerousness of particular stimuli and situations. There is a steadily growing body of evidence showing that parental modeling and threat information transmission can promote fear and anxiety in children (see reviews by $[8,9])$. 
Early studies have typically relied on self-report questionnaires and interviews asking children about these types of learning experiences in relation to their main fear. For instance, in the studies conducted by Ollendick and King [10] and Muris et al. [11], children were first asked to identify their main object of fear, after which they had to indicate to what extent modeling and threat information transmission had played a role in the origins of that fear. It was found that substantial percentages (i.e., 50-90\%) of the children reported such learning experiences, and although their context was not explicitly examined, it is highly plausible that parents were involved.

Subsequent investigations have explored the role of modeling and threat information transmission using experimental designs. With regard to modeling, an exemplary study was conducted by Gerull and Rapee [12] who investigated the influence of fearful responses of mothers to an unknown stimulus on young children's behavior. Fifteen- to 20-months-old toddlers were confronted with rubber toy animals (i.e., spider, snake), while their mother maintained either a negative or a positive facial expression. After a brief delay, children were again exposed to the toy animals to measure fear and avoidance reactions, this time without their mother being present. The results clearly indicated that toddlers for whom the toy animals had been previously paired with a negative facial expression of their mother showed more fear and avoidance than the toddlers for whom the toy animals had been presented with a positive facial expression of their mother (see also [13]).

To directly examine the effects of threat information transmission, Muris et al. [14] adopted a comparable approach. Parents of children aged 8-13 years $(N=88)$ were presented with either negative, positive, or ambiguous information about an unknown animal and were then given a number of open-ended vignettes describing hypothetical confrontations with the animal. Parents were instructed to tell their children what would happen in these situations. Results indicated that children's fear levels were influenced by the type of information that was provided to the parent. That is, parents who had received negative information provided more threatening narratives about the animal and hence installed higher levels of fear in their child than parents who had received positive information. In the case of ambiguous information, the transmission of fear was dependent on parents' trait anxiety levels. More precisely, the higher the trait anxiety level of the parents, the more they were inclined to tell negative stories about the unknown animal on the basis of the ambiguous information, thereby producing higher fear levels in the child. Several other studies have also shown that cognitive biases can be induced in non-anxious individuals by providing them with negative information [15-18].
Thus, there appears to be considerable evidence from both survey and experimental research for the idea that young children can rapidly acquire fear and anxiety via the parental behaviors of modeling and threat information transmission. However, little is known about the mechanisms involved in these ways of fear acquisition. It is wellknown that threat-related cognitive biases are a robust correlate of anxiety pathology in children and adults (see reviews by $[19,20])$. However, only recently studies have begun to explore the possibility that cognitive biases are involved in the intergenerational transfer of fear and anxiety. An investigation by Lester et al. [21] found evidence indicating that the anxiety-related interpretation bias of mothers was not only concerned with self-referent situations, but also with situations that involved their children, suggesting that mothers may extend their own catastrophic cognitive style to the living environment of the children. Another study by Podină et al. [22] took this one step further and actually investigated whether cognitive biases indeed acted as mediators between maternal social anxiety and children's anxiety symptoms. Four-hundred-andtwenty-three mothers and their children completed questionnaires measuring anxiety symptoms and interpretation bias. Multiple mediation analysis demonstrated that both maternal and child interpretation biases were significant mediators in the relation between maternal social anxiety and children's anxiety symptoms. In similar research by Affrunti and Ginsburg [23], it was also demonstrated that interpretation biases acted as the connector between parental and children's anxiety symptoms. A final relevant investigation was recently conducted by Remmerswaal et al. [24] who examined the role of mothers in the development of a cognitive bias and subsequent fear levels in their offspring. Using an inventive experimental design, these researchers were able to show that mothers induced a negative information search bias in their children either on the basis of instruction or driven by their own anxiety, which was also associated with heightened fear levels in relation to a novel stimulus.

The above described research provides support for the idea that cognitive biases play a role in the transfer of fear and anxiety from parents to offspring. The aim of the present cross-sectional study was to further contribute to this literature. In a sample of 258 non-clinical youths aged 9-12 years, fear-enhancing parental variables (i.e., modeling and threat information transmission), children's cognitive biases, and children's and parents' anxiety symptoms were measured. In line with Hadwin et al. [25] who claim that cognitive biases might have their origins in parenting, we hypothesized that these biases would act as a mediator in the link between the parenting behaviors of modeling and threat information transmission and children's anxiety symptoms. 
The current study adds to our existing knowledge in four ways: (1) A newly developed questionnaire was used which made it possible to simultaneously examine both modeling and threat information transmission as predictors of children's cognitive biases and subsequent anxiety symptoms. (2) The fear-enhancing parental behaviors of both parents were investigated, which can be seen as an advancement to previous studies that mainly focused on the role of mothers (e.g., [4]). Note that the comparison between both parents was exploratory in nature and so we did not have an explicit hypothesis. (3) Two types of cognitive biases, interpretation bias and confirmation bias, were assessed. Interpretation bias refers to the inclination to infer threat on the basis of ambiguous information, whereas confirmation bias has to do with the tendency to search for information that confirms one's anxious preconceptions, while ignoring information that could disconfirm threat. Most research has focused on only one type of bias, thereby neglecting the issue of whether such biases are inter-related and make independent contributions to anxiety. Although both interpretation bias and confirmation bias seem to be linked to the interpretation stage of social information processing [26], the present study explored the unique role of both biases as mediators in the relation between fear-enhancing parenting behaviors and children's anxiety symptoms. (4) Because both parents also completed measures of trait anxiety and overprotection, we were also able to investigate to what extent the fear-enhancing parental behaviors of modeling and threat information transmission were associated with these two wellestablished parental correlates of childhood anxiety problems [27, 28]. Based on previous studies we expected that higher levels of fear-enhancing parenting behaviors would be associated with higher levels of trait anxiety and overprotection of parents.

\section{Method}

\section{Participants}

Participants were 258 non-clinical children (132 boys and 126 girls) aged between 7 and 12 years $(M=9.52$, $S D=1.38$ ) and their parents. A total of 199 mothers and 117 fathers (mean ages being 42.20 years, $S D=4.42$ and 44.36 years, $S D=4.95$, respectively, range 28-65 years) also participated in this study. All children had the Dutch nationality and the majority of them were from original Dutch descent $(>95 \%)$. The remainder of the families represented a diversity of nationalities (i.e., German, Belgian, American, Moroccan, Irish, Hungarian, Swedish, and Iraqi). Parental questionnaires were nearly always completed by children's biological parents; the two exceptions were one child who had adoptive parents and one child who was raised by two mothers. The latter child only answered the questions with regard to his biological mother. About $15 \%$ of children came from divorced families.

\section{Child Measures}

The Parental Enhancement of Anxious Cognitions (PEAC) was construed for the purpose of this study. Initially, 23 items were created that referred to the fear-enhancing parental behaviors of modeling and verbal threat information. Two steps were taken to obtain a final version of the scale that we considered as appropriate for our research. The first step involved an inspection of the initial set of PEAC items by two research experts in the field of fear acquisition (prof. Andy Field of Sussex University, Brighton, United Kingdom, and prof. Stanley Rachman of the University of British Columbia, Vancouver, Canada) and 26 clinicians who worked with anxiety disordered children. The two experts helped us to refine and improve the items of the questionnaire, while the clinicians performed a face validity check: they were asked to classify each of the 23 PEAC items as either modeling or threat information transmission. The face validity check was satisfactory: clinicians classified almost all items correctly to either modeling or threat information transmission. The 2 threat information items that were not correctly classified by more than 2 clinicians were removed; these were 2 negatively formulated items and it appeared that they did not load consistently on the two factors. The second step was an exploratory factor analysis (with direct oblimin rotation), which was performed on the PEAC data of the children and their parents. ${ }^{1}$ For children, fathers, and mothers, the factor analysis produced the hypothesized structure with one factor representing modeling behaviors and one threat information transmission. However, 9 items (predominantly negatively formulated items) had to be removed as they did not load consistently on one of the two factors across the three informants. Thus, eventually 14 items were retained in the final version of the PEAC: 6 items pertained to modeling, while 8 items were concerned with threat information transmission (see Appendix). The child version of the PEAC asks children for each item to first rate the frequency of their fathers' and then that of their mothers' fear-enhancing behaviors, using 4-point Likert-scales $(0=$ never, $1=$ sometimes, $2=$ often, and 3 = always). For each factor, a total score can be computed by summing the ratings on relevant items. In the current study, Cronbach's alphas of the child version of the PEAC modeling and threat information transmission

\footnotetext{
1 These data can be obtained from the first author.
} 
factors were .65 and .80 for the mother scales and .66 and .84 for the father scales, indicating that the measure has sufficient to good reliability.

The Revised version of the Screen for Child Anxiety Related Emotional Disorders is an extension of the original SCARED [29, 30] and assesses symptoms of the entire spectrum of DSM-IV-defined [31] anxiety disorders in children and adolescents. In the current study only the SCARED subscales of social phobia (7 items; e.g., "I don't like to be with unfamiliar people"), generalized anxiety disorder (9 items; e.g., "I worry about things working out for me"), and separation anxiety disorder ( 8 items; e.g., "I don't like being away from my family") were used, because these three types of anxiety were considered as most relevant for the scenarios that were employed to assess cognitive biases. Children were asked to rate the frequency with which they experienced each symptom using a three-point scale $(0=$ almost never, $1=$ sometimes, 2 = often) and a total anxiety score can be obtained by summing ratings on the items of the three selected anxiety scales (range 0-48). Research has demonstrated that the SCARED-R has good internal consistency, testretest reliability, and validity [30, 32, 33]. In the current study, the mean total anxiety score on the shortened SCARED was $16.67(S D=8.21)$ and an independent samples $t$-test revealed that girls $(M=18.29, S D=7.94)$ scored higher on this scale than did boys $(M=15.14$, $S D=8.20)[t(256)=3.13, p<.01]$. Further, the reliability of the SCARED-R total anxiety score was good, with a Cronbach's alpha of .87.

The Information Search Task (IST) was also developed for the purpose of this study to assess children's confirmation bias. The task was based on a similar paradigm as used in a previous study [34]. Children were presented with new, potentially threatening situations (e.g., going to a new school) about which they had to gain more information (e.g., "What would you like to know about the teachers at your new school?") by choosing between a positive (e.g., "Whether they have a nice way of teaching") and a negative (e.g., "Whether they become angry very easily") option. After making their choice, children always received a confirmative answer (e.g., positive: "Most teachers have a nice way of teaching", negative: "Most teachers become angry very easily"). In total, children were presented with 3 situations (the other two scenarios were: going to the new warehouse in the city and playing at a friend's home for the first time), for each of which they were able to seek new information 5 times. The types of information the children could collect were related to the different types of anxiety symptoms. A confirmation bias score was computed by summing the number of negative options chosen (range 0-15). The reliability of the IST was acceptable, with a Cronbach's alpha of .72.
To assess interpretation bias, we used three Ambiguous Stories [35], which represented the themes of social anxiety (i.e., going to a sporting club for the first time), generalized anxiety (i.e., driving with your bike on a very busy street), and separation anxiety (i.e., staying with a friend while parents are on vacation). Children had to read the stories, which consisted of five sentences presented to them sentence by sentence on the computer screen. Following each sentence, they were asked whether they thought that the story would be "scary" or "not scary". A total interpretation bias score was calculated by summing up the number of sentences after which children indicated the story was going to be scary (range 0-15). The reliability of the Ambiguous Stories test was sufficient, with a Cronbach's alpha of .63.

\section{Parent Measures}

The Y2-version of the Spielberger State-Trait Anxiety Inventory (STAI; [36, 37]) was used to assess trait anxiety in the parents. The questionnaire includes 20 items (e.g., "I feel nervous" and "I worry too much about little things") for which respondents have to indicate their answer on a four-point Likert type scale $(1=$ almost never, $2=$ sometimes, $3=$ often, $4=$ almost always). After recoding the positively phrased items, a total score can be obtained by summing all items (range 20-80). There is clear support for the psychometric properties of the STAI [36, 38]. Cronbach's alphas in the present sample were .92 for the mothers and .94 for the fathers, indicating excellent reliability.

The Parental Overprotection Measure (POM; [39]) was used to measure overprotective parenting behaviors which are thought to restrict the child's exposure to situations that are perceived as threatening or harmful. The instrument consists of 19 items (e.g., "I do not allow my child to climb in trees" and "I protect my child from criticism") that are scored on a five-point Likert scale $(0=$ not at all, $1=\mathrm{a}$ little, 2 = somewhat, $3=$ quite often, $4=$ very often). A total score can be obtained by summing all items (range 0-76). The scale has been shown to possess high internal consistency, strong test-retest reliability, and good validity [39]. In the current study reliability was also good, with Cronbach's alphas of .88 for the mothers and .87 for the fathers.

A parent version of the Parental Enhancement of Anxious Cognitions (PEAC) was also completed by the parents. The scale is similar to the one completed by the children, but the 14 items are formulated from the perspective of the parent (e.g., "I warn my child explicitly that he/she should avoid dangerous situations" instead of "My mother/father warns me explicitly that I should avoid dangerous situations"). Cronbach's alphas of the modeling and threat 
information transmission factors were .77 and .81 for the mother scales and .68 and .72 for the father scales, indicating that the parent version of the PEAC has sufficient to good reliability.

\section{Procedure}

Participants were recruited via four Dutch primary schools. Informed parental consent was obtained by sending parents an information letter about the study with a consent form. Children for whom parents granted permission were tested in small groups (of approximately eight children per group) in a separate room in school. Each child used a computer to fill out the questionnaires and to conduct the cognitive bias tasks. This assessment took place under supervision of two experimenters, who guided the children through the session by providing instructions and by collectively conducting some practice items. The children received explicit instructions to call upon the experimenters in case they had any questions about the scales or tasks. The experimenters ensured that the children answered the questions and conducted the computer tasks confidentially and independently. Children first completed the SCARED and the PEAC, after which they carried out the IST and the Ambiguous Stories test. Children did not appear to experience great difficulties while completing the questionnaires and computer tasks. Some children had questions about how to fill out the negatively formulated items of the PEAC (most of these items were eventually removed during the factor analyses). Parents completed the questionnaires at home on their own computer using a web-link provided to them by the experimenters.

\section{Statistical Analyses}

$T$-tests and correlations were computed to investigate possible differences and links among various child and parent scales. To investigate whether the two cognitive biases acted as mediators in the relation between modeling and threat information transmission on the one hand and anxiety symptoms of the child on the other hand, we conducted a bootstrapping procedure for multiple mediators [40] using the child-report data. We used the SPSS macro relying on a method with 1000 bootstrap resamples to test the indirect effects of modeling and threat information transmission via the potential mediating variables on child anxiety. The output provides a $95 \%$ confidence interval of the indirect effects, controlling for the effects of the other variables. If zero is not included in the confidence interval, the effect is considered significant. This means that the effect of the independent variable (modeling or threat information) on the dependent variable (child anxiety) is mediated by the proposed mediators (confirmation bias or interpretation bias). We conducted four different analyses: one for each independent parenting variable of mothers and fathers.

\section{Results}

\section{General Results}

Before discussing the main findings of the present study, a number of general results will be addressed. First, $t$-tests comparing the levels of modeling and threat information transmission between fathers and mothers revealed significant differences when these parenting behaviors were assessed from the child's perspective. As can be seen in Table 1, children indicated that their mothers more often displayed modeling $[t(248)=9.39, p=.01]$ and threat information transmission $[t(248)=9.29, p=.01]$ than their fathers. When using the parents' point-of-view, no significant differences between fathers and mothers were observed, although a trend was noted signaling somewhat higher levels of threat information transmission in fathers than in mothers $[t(105)=1.93, p=.06]$. No differences were found between fathers and mothers with regard to trait anxiety or overprotective parenting [both $t(106)$ 's $<1$; see Table 1].

Second, a statistical comparison of the PEAC scores of children and parents indicated that children scored their mothers as higher on both modeling $[t(198)=5.70$, $p<.001]$ and threat information transmission $[t(198)=6.43, \quad p<.001] \quad$ than mothers themselves (Table 1). No such differences were observed when

Table 1 Mean scores (standard deviations) on parent-related questionnaires as completed by parents and children separately, as well as reliability coefficients for various scales

\begin{tabular}{lclll}
\hline & Mothers & $\alpha$ & Fathers & $\alpha$ \\
\hline Children & & & & \\
PEAC modeling & $10.77(3.14)^{\mathrm{a}}$ & .65 & $9.39(2.82)^{\mathrm{b}}$ & .66 \\
PEAC threat info & $22.94(4.96)^{\mathrm{a}}$ & .80 & $21.14(5.44)^{\mathrm{b}}$ & .84 \\
Parents & & & & \\
PEAC modeling & $9.40(2.69)^{\mathrm{b}}$ & .77 & $9.19(2.46)^{\mathrm{b}}$ & .68 \\
PEAC threat info & $20.24(4.27)^{\mathrm{b}}$ & .81 & $20.97(3.54)^{\mathrm{b}}$ & .72 \\
STAI trait anxiety & $31.90(8.12)$ & .92 & $31.86(8.88)$ & .94 \\
POM overprotection & $24.12(10.40)$ & .88 & $25.06(10.08)$ & .87 \\
\hline
\end{tabular}

$N$ 's were 199 for mothers, 117 for fathers and 258 for children

a, b For each type of fear-enhancing parenting behavior, within-row and within column means not sharing similar superscripts differ at $p<.01$

STAI State-Trait Anxiety Inventory, POM Parental Overprotection Measure, PEAC Parental Enhancement of Anxious Cognitions, Threat info Threat information transmission 
comparing the PEAC scores between children and fathers [both $t(115)$ 's $\leq 1.56, p$ 's $\geq .12$ ].

\section{Correlation Analysis}

Table 2 displays correlations among various child and parent measures included in this study. A number of conclusions can be drawn from this table. When looking at the correlations obtained among the child measures, it can first of all be concluded that fear-enhancing parenting behaviors of fathers and mothers were positively and significantly correlated (all $r$ 's between .31 and .83 , $p$ 's $<.01$ ). Thus, according to the children, mothers' and fathers' modeling and negative information transmission were moderately to strongly associated. Fear-enhancing parenting behaviors were also positively related to children's anxiety symptoms ( $r$ 's between .32 and $.37, p$ 's $<.01$ ), implying that the more children perceived modeling and negative information transmission in fathers and mothers, the higher their levels of anxiety symptoms. Further, children's anxiety symptoms were also positively linked to cognitive bias scores ( $r$ 's $=.31$ and .49 , $p$ 's $<.01$ ). That is, higher levels of anxiety symptoms were accompanied by higher levels of threatening interpretations of ambiguous stories (i.e., interpretation bias) and a stronger tendency to search for negative information (i.e., confirmation bias). Finally, a small but significant positive correlation was found between both types of cognitive biases $(r=.20, p<.01)$,

Table 2 Correlations among all child and parent measures

\begin{tabular}{|c|c|c|c|c|c|c|c|c|c|c|c|c|c|c|}
\hline & (1) & (2) & (3) & (4) & (5) & (6) & (7) & (8) & (9) & (10) & (11) & (12) & (13) & (14) \\
\hline \multicolumn{15}{|l|}{ Child } \\
\hline \multicolumn{15}{|l|}{$\begin{array}{l}\text { 1. Confirmation } \\
\text { bias }\end{array}$} \\
\hline $\begin{array}{l}\text { 2. Interpretation } \\
\text { bias }\end{array}$ & $.20 * *$ & & & & & & & & & & & & & \\
\hline $\begin{array}{l}\text { 3. PEAC } \\
\text { modeling M }\end{array}$ & $.18 * *$ & $.27 * *$ & & & & & & & & & & & & \\
\hline $\begin{array}{l}\text { 4. PEAC } \\
\text { modeling } \mathrm{F}\end{array}$ & $.17 * *$ & $.20 * *$ & $.70 * *$ & & & & & & & & & & & \\
\hline $\begin{array}{l}\text { 5. PEAC threat } \\
\text { info } \mathrm{M}\end{array}$ & $.33 * *$ & $.25^{* *}$ & $.47 * *$ & $.37 * *$ & & & & & & & & & & \\
\hline $\begin{array}{l}\text { 6. PEAC threat } \\
\text { info } F\end{array}$ & $.29 * *$ & $.26 * *$ & $.31 * *$ & $.44 * *$ & $.83 * *$ & & & & & & & & & \\
\hline $\begin{array}{l}\text { 7. SCARED } \\
\text { total anxiety }\end{array}$ & $.31 * *$ & $.49 * *$ & $.37 * *$ & $.36^{* *}$ & $.33 * *$ & $.32 * *$ & & & & & & & & \\
\hline \multicolumn{15}{|l|}{ Mother } \\
\hline $\begin{array}{l}\text { 8. STAI Trait } \\
\text { anxiety }\end{array}$ & .06 & .02 & .00 & -.03 & .00 & -.04 & .02 & & & & & & & \\
\hline $\begin{array}{l}\text { 9. POM } \\
\text { overprotection }\end{array}$ & .00 & .05 & $.14 *$ & $.16^{*}$ & .08 & .06 & .12 & $.20 * *$ & & & & & & \\
\hline $\begin{array}{l}\text { 10. PEAC } \\
\text { Modeling }\end{array}$ & -.05 & .06 & $.25^{* *}$ & .06 & .09 & -.08 & .11 & $.28 * *$ & $.20 * *$ & & & & & \\
\hline $\begin{array}{l}\text { 11. PEAC threat } \\
\text { info }\end{array}$ & .07 & .04 & $.14 *$ & .11 & $.15^{*}$ & .10 & $.17 *$ & $.14 *$ & $.60 * *$ & $.40 * *$ & & & & \\
\hline \multicolumn{15}{|l|}{ Father } \\
\hline $\begin{array}{l}\text { 12. STAI trait } \\
\text { anxiety }\end{array}$ & -.13 & -.03 & .00 & .11 & -.16 & -.12 & -.06 & $.20 *$ & -.02 & -.05 & -.12 & & & \\
\hline $\begin{array}{l}\text { 13. POM } \\
\text { overprotection }\end{array}$ & .04 & -.14 & -.11 & .03 & .09 & .15 & .05 & .10 & $.38^{*}$ & -.13 & .10 & .06 & & \\
\hline $\begin{array}{l}\text { 14. PEAC } \\
\text { modeling }\end{array}$ & .04 & -.03 & .16 & $.28 * *$ & .09 & .10 & .03 & -.08 & -.04 & .12 & .04 & $.23 *$ & .06 & \\
\hline $\begin{array}{l}\text { 15. PEAC threat } \\
\text { info }\end{array}$ & .09 & -.04 & -.12 & -.08 & .11 & .13 & -.05 & -.01 & .17 & -.08 & .15 & .04 & $.55 * *$ & .14 \\
\hline
\end{tabular}

$N$ 's were 199 for mothers, 117 for fathers and 258 for children

PEAC Parental Enhancement of Anxious Cognitions, Threat info threat information transmission, $M$ child about mother, $F$ child about father, SCARED Screen for Child Anxiety Related Disorders, STAI State-Trait Anxiety Inventory, POM Parental Overprotection Measure

$* p<.05$, ** $p<.01$ 
meaning that a stronger inclination towards threat interpretation was also to some extent associated with a stronger tendency to search for negative information.

The correlations among the scales as completed by the mothers revealed the expected pattern of positive links among trait anxiety, overprotection, and the fear-enhancing parental behaviors of modeling and negative information transmission. Most of these correlations were in the small to moderate range, but in particular the correlation between overprotection and threat information transmission was quite robust $(r=.60, p<.001)$. In fathers, the correlations among parental indices were less clear. Only a small correlation between trait anxiety and modeling was found ( $r=.23, p<.05)$, whereas the link between overprotection and threat information transmission was again substantial $(r=.55, p<.001)$.

When looking at the cross-informant correlations in Table 2, the overall conclusion is that few significant associations between child- and parent-reports and between measures of mothers and fathers were found. As for fearenhancing parenting, significant correlations emerged for modeling of mothers and fathers as reported by the children and modeling as reported by mothers and fathers themselves ( $r$ 's being .25 and .28 , respectively, $p$ 's $<.01$ ). In addition, threat information transmission of mothers as reported by the children was positively linked to threat information transmission as reported by mothers themselves, although the magnitude of this correlation was small $(r=.15, p<.05)$. Fathers and mothers did show some similarity with regard to their level of trait anxiety and overprotective parenting ( $r$ 's being .20 and .38, $p$ 's $<.05$ ), but for the fear-enhancing behaviors of modeling and threat information transmission correlations between fathers and mothers were non-significant. Finally, parental indices and children's anxiety symptoms and cognitive biases were largely unrelated, except for a small positive correlation between threat information transmission of mothers and children's anxiety symptoms $(r=.17$, $p<.05)$.

\section{The Mediating Role of Cognitive Biases}

The results of the mediation analyses are presented in Table 3. In the first analysis, threat information transmission of mothers was the independent variable. The indirect effects of confirmation bias (bias corrected $95 \% \mathrm{CI}=.02$, .10 ) and interpretation bias (bias corrected $95 \% \mathrm{CI}=.01$, .12) were both significant. The direct effect was not significant, which implies that these cognitive biases mediated the relationship between maternal threat information transmission and child anxiety. In the second analysis, modeling of mothers was the independent variable. Only the indirect effect of interpretation bias was found to be significant (bias corrected $95 \% \mathrm{CI}=.03, .14$ ). Here, the direct effect still accounted for a significant proportion of the variance in children's anxiety symptoms.

In the third analysis, threat information transmission of fathers was the independent variable. Both the indirect effects of confirmation bias (bias corrected $95 \% \mathrm{CI}=.02$, .09 ) and interpretation bias (bias corrected $95 \% \mathrm{CI}=.03$, .16) were significant. As the direct effect was non-significant, it can be concluded that both cognitive biases mediated the relationship between paternal threat information transmission and child anxiety. In the final analysis, modeling of fathers was the independent variable. The indirect effects for confirmation bias (bias corrected $95 \%$

Table 3 Results of the bootstrapping analyses testing cognitive biases as mediators between child-reported threat information transmission and modeling of parents and children's anxiety symptoms

\begin{tabular}{|c|c|c|c|c|c|c|}
\hline IV & M & Effect of IV on M & Effect of $\mathrm{M}$ on DV & Direct effect & Indirect effect & Total effect \\
\hline \multicolumn{7}{|l|}{ Mothers } \\
\hline \multirow[t]{2}{*}{ Threat information } & Confirmation bias & $.31 * * *$ & $.17 * *$ & .09 & $.05^{\mathrm{a}}$ & $.20 * *$ \\
\hline & Interpretation bias & $.16^{*}$ & $.39 * * *$ & & $.16^{\mathrm{a}}$ & \\
\hline \multirow[t]{2}{*}{ Modeling } & Confirmation bias & .03 & $.17 * *$ & $.19 * *$ & .01 & $.28 * * *$ \\
\hline & Interpretation bias & $.20 * *$ & $.39 * * *$ & & $.08^{\mathrm{a}}$ & \\
\hline \multicolumn{7}{|l|}{ Fathers } \\
\hline \multirow[t]{2}{*}{ Threat information } & Confirmation bias & $.26 * * *$ & $.18^{* *}$ & .06 & $.05^{\mathrm{a}}$ & $.20 * *$ \\
\hline & Interpretation bias & $.21 * *$ & $.42 * * *$ & & $.09^{\mathrm{a}}$ & \\
\hline \multirow[t]{2}{*}{ Modeling } & Confirmation bias & .05 & $.18 * *$ & $.21 * * *$ & .01 & $.27 * * *$ \\
\hline & Interpretation bias & .11 & $.42 * * *$ & & .05 & \\
\hline
\end{tabular}

$I V$ independent Variable, $M$ mediator, $D V$ dependent variable

${ }^{a}$ Significant point estimate $(p<.05)$

$* p<.05, * * p<.01, * * * p<.001$ 
$\mathrm{CI}=-.01, .04$ ) and interpretation bias (bias corrected $95 \% \mathrm{CI}=-.01, .11)$ were not significant, which means that there was no indication for a mediation effect.

\section{Discussion}

The aim of the present study was to examine whether cognitive biases play a role in the transfer of fear and anxiety from parents to offspring. More specifically, it was investigated whether confirmation bias and interpretation bias would act as mediators in the relation between the fear-enhancing parenting behaviors of modeling and threat information transmission and anxiety symptoms in children. The results first of all showed that child-reported modeling and threat information transmission of fathers and mothers were positively related to children's anxiety symptoms. Thus, children who indicated that their parents often acted as an anxious model or frequently communicated threat information also displayed higher levels of anxiety. Further, evidence was found indicating that both confirmation and interpretation bias mediated the relationship between threat information transmission of both mother and father and children's anxiety symptoms, which is in keeping with other studies investigating the mediational role of cognitive bias in the relation between parenting behaviors and childhood anxiety problems [41-43]. The support for a mediating role of cognitive bias in the relation between modeling and children's anxiety symptoms was less convincing. Only interpretation bias mediated the relationship between modeling of mothers (but not of fathers) and children's anxiety symptoms. Remarkably, the direct effect of modeling on children's anxiety symptoms still accounted for a significant proportion of the variance in the models of both the mothers and the fathers. This implies that parental modeling does not solely exert its impact via children's cognitive biases, but suggests other mediators (or moderators) to be involved in the relation between maternal modeling and children's anxiety symptoms.

It is unclear why cognitive biases played a more important role in the relation between parental threat information transmission and children's anxiety symptoms than it did in the relation between parental modeling and children's anxiety symptoms. A plausible explanation has to do with the fact that cognitive biases are verbal in nature, and this might be the modus operandi of threat information transmission. That is, parents verbally communicate threat information to the child, thereby having a direct impact on the cognitions of their offspring. The mechanism involved in the relation between modeling and child anxiety seems to be quite different. Illustrative in this regard is the research on social referencing; children observe their mothers reacting with fear and anxiety to a certain stimulus or situation, and subsequently start to copy that anxious behavior when they are exposed to that stimulus or situation themselves [44]. This mechanism already occurs in children at a young age and seems less cognitive, but above all emotional-behavioral in nature.

The pattern of the effects in the mediation models was more or less comparable for both parents. It may well be the case that the contributions of fathers and mothers to children's anxiety symptoms are made via the same mechanisms. However, one should also be aware of the possibility that similarities in findings for mothers and fathers might have been mainly due to the fact that these analyses only relied on the child-report data, for which the mother and father ratings on the PEAC were highly correlated. The cross-informant (i.e., child-father, childmother) correlations in general yielded few significant findings (see review by [45]), and thus were less suitable for studying differential findings between both parents. It would have been interesting if we had assessed all constructs (that is, not only fear-enhancing parenting behaviors, but also children's cognitive biases and anxiety symptoms) from both parents' point-of-view, and this is an important venue for further research.

When looking at the PEAC data, a number of additional findings should be noted. First, according to the children, mothers displayed more modeling and threat information transmission than fathers, which is of course in keeping with the literature indicating that females (mothers) generally display higher levels of fear and anxiety and are probably more likely to engage in fear-enhancing behaviors than males [46]. However, when looking at the parental data, no evidence was found for this idea: that is, mothers and fathers did not only report equal levels of modeling and threat information transmission, but also did not differ in terms of trait anxiety and overprotection. It is not clear why children rated their mothers as higher on fear-enhancing behaviors, but one explanation could be that mothers more often act as the primary caretaker and thus spent more time with their children [47]. It is possible that for this reason children could think of more examples when evaluating the behaviors of their mothers and as such provided higher ratings of modeling and threat information transmission. Second, the child-parent and mother-father correlations for the PEAC scales were rather low or nonsignificant. Again, this is in line with previous findings and indicates that informant discrepancies not only occur when assessing childhood symptoms but also when measuring contextual, etiological factors, such as fear-enhancing parental behaviors. Third, when looking at the relations between the PEAC scales and two well-known parental correlates of childhood anxiety symptoms, namely parental trait anxiety and overprotective parenting [27, 28], the 
mother data clearly showed the predicted pattern of findings. That is, positive and significant correlations emerged among modeling, threat information transmission, trait anxiety, and overprotection. The father data only revealed significant correlations between trait anxiety and modeling, and between overprotection and threat information transmission. Obviously, these results provide some support for the validity of the PEAC scales. The fact that the most robust correlation (for both mothers and fathers) was found between overprotection and threat information transmission makes sense, and seems to point out that parents especially try to shield their offspring against potential danger by providing them with threatening information.

The two types of cognitive biases, interpretation bias and confirmation bias, were only moderately correlated. The modest overlap between both biases was also confirmed in the mediation analyses, which showed that interpretation bias and confirmation bias each made their own unique contributions as mediators in the relation between parental fear-enhancing behaviors and children's anxiety symptoms. Since interpretation and confirmation bias are both thought to occur during the more conceptual stages of information processing $[20,26]$, we had expected to find a higher correlation between these biases. So far, few other studies have explored the relations among (children's) cognitive biases and the unique links of these biases to anxiety disorders symptoms. One exception is an investigation by Dalgleish et al. [48] who also documented small, mostly non-significant correlations among various types of biases in a sample of youth with mixed internalizing disorders. These authors argued that this may have been primarily due to the fact that these biases are measured with different experimental tasks, thereby introducing quite a large amount of non-shared variance which leads to fairly low inter-correlations among various biases. Obviously, this argument is also true for the two biases that were investigated in the present study.

The assessment of multiple cognitive biases was certainly a strong point of this study as was the inclusion of both mothers and fathers. However, the present investigation also suffers from a number of limitations. To begin with, this was a cross-sectional study, which means that no conclusions about the directionality of the relationships can be drawn. Obviously, a longitudinal set-up is needed, a requirement which will be met as we are planning a followup assessment of this sample. A further shortcoming has already been mentioned and is concerned with the fact that we did not take all the assessments in every informant. Moreover, it would have been preferable if we had not only relied on rating scales for measuring modeling and threat information transmission, but had also employed some kind of interview or observational method to assess these fear-enhancing parental behaviors. More specifically, children could either be asked open-ended questions to learn more about how their parents discourage various behaviors or how threatening their parents view the world (e.g., new places, unfamiliar people, risky situations), or child-parent interactions could be observed in challenging situations. Apart from the fact that such a multi-method approach is preferable, this would also give us the opportunity to study the validity of the PEAC more thoroughly. Furthermore, the reliability coefficients of the modeling subscale of the PEAC, in particular for the child and father data, were on the low side. The most plausible explanation might be that the modeling scale consists of only a limited set of items that are quite heterogeneous in terms of content. That is, modeling items refer to parents' concealed fear reactions, facial expression, body language, and panic symptoms, which may not all be equally well observed and scored, especially by children. Another shortcoming of the study has to do with the fixed sequence in which the questionnaires were administered, which may have introduced some unintended order effects. For example, responding to SCARED social anxiety items may have primed children's responses on the bias tasks, which were partly geared to assess children's responses to scenarios depicting social situations. Finally, children's PEAC scores for mothers and fathers were strongly correlated, which may be the result of the method of scoring each item simultaneously for both parents (left on the screen: father, right on the screen: mother). For future studies, it would be better to present the father and mother versions of this questionnaire serially instead of parallel.

This cross-sectional study is the first to explore relations between parental modeling and verbal threat information and child anxiety symptoms, while taking into account the role of two types of cognitive biases: confirmation bias and interpretation bias. Some evidence was provided for a mediating role of cognitive biases in the relation between threat information transmission and child anxiety. This suggests that intervention programs targeting anxiety problems of children via the parents should target the threat information transmission pathway if one intends to produce cognitive change, whereas a focus on the modeling pathway is required to produce behavioral change. Future research should explore this possibility in anxious children of various ages.

\section{Summary}

Parents are thought to be involved in the etiology of anxiety pathology in children. This cross-sectional study explored whether parental modeling and threat information transmission would be positively related to anxiety symptoms in children. It was hypothesized that this relationship 
would be mediated by children's cognitive biases. Participants consisted of 258 children aged between 7 and 12 years and their parents. Children and parents completed the Parental Enhancement of Anxious Cognitions questionnaire, which measures parental modeling and threat information transmission, while children also filled in a scale for assessing anxiety disorder symptoms. In addition, children conducted a number of computerized tasks for measuring confirmation and interpretation bias. Evidence was found for a mediating role of cognitive biases in the relation between threat information transmission and child anxiety, but the support for a mediating role of cognitive bias in the relation between modeling and child anxiety was less convincing. A possible explanation for this finding might be that cognitive biases as well as threat information transmission are more verbal in nature, while the mechanism involved in the relation between modeling and child anxiety seems to be quite different. Modeling is probably more related to social referencing, which is a topic in need of further scientific inquiry. Our data provide more insight in the relations between fear-enhancing parenting behaviors, cognitive biases, and anxiety symptoms in children.

Open Access This article is distributed under the terms of the Creative Commons Attribution 4.0 International License (http://crea tivecommons.org/licenses/by/4.0/), which permits unrestricted use, distribution, and reproduction in any medium, provided you give appropriate credit to the original author(s) and the source, provide a link to the Creative Commons license, and indicate if changes were made.

\section{Appendix}

See Table 4.

Table 4 Parental Enhancement of Anxious Cognitions (PEAC)

\begin{tabular}{|c|c|c|c|c|c|c|c|}
\hline \multicolumn{4}{|l|}{ Father } & \multicolumn{4}{|l|}{ Mother } \\
\hline $\begin{array}{l}\text { Not at } \\
\text { all true } \\
(0)\end{array}$ & $\begin{array}{l}\text { Somewhat } \\
\text { true (1) }\end{array}$ & $\begin{array}{l}\text { True } \\
\text { (2) }\end{array}$ & $\begin{array}{l}\text { Very } \\
\text { true } \\
(3)\end{array}$ & $\begin{array}{l}\text { Not at } \\
\text { all true } \\
(0)\end{array}$ & $\begin{array}{l}\text { Somewhat } \\
\text { true (1) }\end{array}$ & $\begin{array}{l}\text { True } \\
\text { (2) }\end{array}$ & $\begin{array}{l}\text { Very } \\
\text { true } \\
(3)\end{array}$ \\
\hline
\end{tabular}

1. This parent warns me about potential dangers, to prevent accidents from happening

2. When I am anxious to do something, this parent cannot conceal his/her worries

3. This parent explicitly warns me that I should be careful when I leave home

4. This parent warns me that I should never talk to strangers because of bad things that might happen

5. When this parent is scared, his/her body language reveals his/her fear (e.g., fidgeting hands, sweating, trembling, touching neck or face)

6. This parent shows when he/she is in panic in my presence

7. When this parent is scared, he/she has a fearful expression on his/her face in my presence

8. This parent shows me that he/she is afraid to do certain things

9. This parent warns me explicitly that I should avoid dangerous situations

10. This parent tells me that the world is not always a safe place

11. Even if this parent tries to hide his/her fear, I can still see that he/she is anxious

12. When I do something new or go to a new place, this parent warns me about the things that could go wrong

13. This parent points out to me that an accident can always happen

14. This parent warns me explicitly not to go along with unfamiliar people

Threat information transmission: items 1, 3, 4, 9, 10, 12, 13, 14; Modeling: items 2, 5, 6, 7, 8, 11 


\section{References}

1. Muris P (2007) Normal and abnormal fear and anxiety in children and adolescents. Elsevier, Oxford

2. Eley TC, Gregory AM (2004) Behavioral genetics, in Anxiety disorders in children and adolescents. Guilford Press, New York, pp 71-97

3. Murray L, Creswell C, Cooper PJ (2009) The development of anxiety disorders in childhood: an integrative review. Psychol Med 39:1413-1423

4. Bögels S, Phares V (2008) Fathers' role in the etiology, prevention and treatment of child anxiety: a review and new model. Clin Psychol Rev 28:539-558

5. Fliek L, Daemen E, Roelofs J, Muris P (2014) Rough-and-tumble play and other parental factors as correlates of anxiety symptoms in preschool children. J Child Family Stud 24:2795-2804

6. Rachman S (1977) The conditioning theory of fearacquisition: a critical examination. Behav Res Ther 15:375-387

7. Rachman S (1991) Neo-conditioning and the classical theory of fear acquisition. Clin Psychol Rev 11:155-173

8. Askew C, Field AP (2008) The vicarious learning pathway to fear 40 years on. Clin Psychol Rev 28:1249-1265

9. Muris P, Field AP (2010) The role of verbal threat information in the development of childhood fear. "Beware the Jabberwock!". Clin Child Fam Psychol Rev 13:129-150

10. Ollendick TH, King NJ (1991) Origins of childhood fears: an evaluation of Rachman's theory of fear acquisition. Behav Res Ther 29:117-123

11. Muris P, Merckelbach H, Collaris R (1997) Common childhood fears and their origins. Behav Res Ther 35:929-937

12. Gerull FC, Rapee RM (2002) Mother knows best: effects of maternal modelling on the acquisition of fear and avoidance behaviour in toddlers. Behav Res Ther 40:279-287

13. Dubi K, Rapee R, Emerton J, Schniering C (2008) Maternal modeling and the acquisition of fear and avoidance in toddlers: influence of stimulus preparedness and child temperament. J Abnorm Child Psychol 36:499-512

14. Muris P, van Zwol L, Huijding J, Mayer B (2010) Mom told me scary things about this animal: parents installing fear beliefs in their children via the verbal information pathway. Behav Res Ther 48:341-346

15. Muris P, Huijding J, Mayer B, Hameetman M (2008) A space odyssey: experimental manipulation of threat perception and anxiety-related interpretation bias in children. Child Psychiatry Hum Dev 39:469-480

16. Muris P, Huijding J, Mayer B, Remmerswaal D, Vreden S (2009) Ground control to Major Tom: experimental manipulation of anxiety-related interpretation bias by means of the "space odyssey" paradigm and effects on avoidance tendencies in children. J Anxiety Disord 23:333-340

17. Muris P, Rassin E, Mayer B, Smeets G, Huijding J, Remmerswaal $D$ et al (2009) Effects of verbal information on fear-related reasoning biases in children. Behav Res Ther 47:206-214

18. Remmerswaal D, Muris P, Mayer B, Smeets G (2010) "Will a Cuscus bite you, if he shows his teeth?" Inducing a fear-related confirmation bias in children by providing verbal threat information to their mothers. J Anxiety Disord 24:540-546

19. Mathews A, Mackintosh B, Fulcher EP (1997) Cognitive biases in anxiety and attention to threat. Trends Cogn Sci 1:340-345

20. Muris P, Field AP (2008) Distorted cognition and pathological anxiety in children and adolescents. Cogn Emot 22:395-421

21. Lester KJ, Field AP, Cartwright-Hatton S (2012) Maternal anxiety and cognitive biases towards threat in their own and their child's environment. J Fam Psychol 26:756-766
22. Podină IR, Mogoaşe C, Dobrean A (2013) Intergenerational transmission of anxiety: evidence for the mediating role of the negative interpretation bias. J Cogn Behav Psychother 13:309-320

23. Affrunti NW, Ginsburg GS (2012) Exploring parental predictors of child anxiety: The mediating role of child interpretation bias. In: Child \& youth care forum. Springer

24. Remmerswaal D, Muris P, Huijding J (2015) Transmission of cognitive bias and fear from parents to children: an experimental study. J Clin Child Adolesc Psychol. doi:10.1080/15374416. 2014.987378

25. Hadwin JA, Garner M, Perez-Olivas G (2006) The development of information processing biases in childhood anxiety: a review and exploration of its origins in parenting. Clin Psychol Rev 26:876-894

26. Crick NR, Dodge KA (1994) A review and reformulation of social information-processing mechanisms in children's social adjustment. Psychol Bull 115:74-101

27. Hudson JL, Rapee RM (2001) Parent-child interactions and anxiety disorders: an observational study. Behav Res Ther 39:1411-1427

28. Last CG, Hersen M, Kazdin A, Orvaschel H, Perrin S (1991) Anxiety disorders in children and their families. Arch Gen Psychiatry 48:928-934

29. Birmaher B, Khetarpal S, Brent D, Cully M, Balach L, Kaufman J et al (1997) The Screen For Child Anxiety Related Emotional Disorders (SCARED): scale construction and psychometric characteristics. J Am Acad Child Adolesc Psychiatry 36:545-553

30. Muris P, Merckelbach H, van Brakel A, Mayer B (1999) The revised version of the screen for child anxiety related emotional disorders (SCARED-R): further evidence for its reliability and validity. Anxiety Stress Coping 12:411-425

31. American Psychiatric Association (2013) Diagnostic and statistical manual of mental disorders, 5th edn. American Psychiatric Publishing, Arlington

32. Muris P, Dreessen L, Bögels S, Weckx M, van Melick M (2004) A questionnaire for screening a broad range of DSM-defined anxiety disorder symptoms in clinically referred children and adolescents. J Child Psychol Psychiatry 45:813-820

33. Muris P, Merckelbach H, Schmidt H, Mayer B (1999) The revised version of the Screen for Child Anxiety Related Emotional Disorders (SCARED-R): factor structure in normal children. Pers Individ Dif 26:99-112

34. Remmerswaal D, Huijding J, Bouwmeester S, Brouwer M, Muris P (2014) Cognitive bias in action: evidence for a reciprocal relation between confirmation bias and fear in children. $\mathrm{J}$ Behav Ther Exp Psychiatry 45:26-32

35. Muris P, Rapee R, Meesters C, Schouten E, Geers M (2003) Threat perception abnormalities in children: the role of anxiety disorders symptoms, chronic anxiety, and state anxiety. J Anxiety Disord 17:271-287

36. Spielberger CD, Gorsuch RL, Lushene R, Vagg PR, Jacobs GA (1983) Manual for the State-Trait Anxiety Inventory (form Y). Consulting Psychologists Press, Palo Alto

37. Van der Ploeg HM, Defares PB, Spielberger CD (1980) Handleiding bij de zelfbeoordelingsvragenlijst, ZBV: een Nederlandse vertaling van de Spielberger State-Trait Anxiety Inventory. Swets \& Zeitlinger, Lisse

38. Bieling PJ, Antony MM, Swinson RP (1998) The State-Trait Anxiety Inventory, Trait version: structure and content re-examined. Behav Res Ther 36:777-788

39. Edwards SL, Rapee RM, Kennedy SJ (2008) Psychometric properties of a parent-report measure of overprotection of preschool-aged children. Manuscript submitted for publication

40. Preacher KJ, Hayes AF (2008) Asymptotic and resampling strategies for assessing and comparing indirect effects in multiple mediator models. Behav Res Methods 40:879-891 
41. Gallagher B, Cartwright-Hatton S (2008) The relationship between parenting factors and trait anxiety: mediating role of cognitive errors and metacognition. J Anxiety Disord 22:722-733

42. Pereira AI, Barros L, Mendonça D, Muris P (2014) The relationships among parental anxiety, parenting, and children's anxiety: the mediating effects of children's cognitive vulnerabilities. J Child Family Stud 23:399-409

43. Perez-Olivas G, Stevenson J, Hadwin JA (2008) Do anxiety-related attentional biases mediate the link between maternal over involvement and separation anxiety in children? Cogn Emot 22:509-521

44. de Rosnay M, Cooper PJ, Tsigaras N, Murray L (2006) Transmission of social anxiety from mother to infant: an experimental study using a social referencing paradigm. Behav Res Ther 44:1165-1175
45. De Los Reyes A, Kazdin AE (2005) Informant discrepancies in the assessment of childhood psychopathology: a critical review, theoretical framework, and recommendations for further study. Psychol Bull 131:483

46. Craske MG (2003) Origins of phobias and anxiety disorders: Why more women than men?. Elsevier, Oxford

47. Lamb ME (2000) The history of research on father involvement: an overview. Marriage Fam Rev 29:23-42

48. Dalgleish T, Taghavi R, Neshat-Doost H, Moradi A, Canterbury R, Yule W (2003) Patterns of processing bias for emotional information across clinical disorders: a comparison of attention, memory, and prospective cognition in children and adolescents with depression, generalized anxiety, and posttraumatic stress disorder. J Clin Child Adolesc Psychol 32:10-21 